Mehmet Akif Ersoy Üniversitesi Fen Bilimleri Enstitüsü Dergisi 9(1): 22-28 (2018)

The Journal of Graduate School of Natural and Applied Sciences of Mehmet Akif Ersoy University 9(1): 22-28 (2018)

\author{
Araştırma Makalesi / Research Paper
}

\title{
Karacaören I Baraj Gölünün Kuş Faunası
}

\author{
Halil SÜEL ${ }^{1 *}$, İdris OĞURLU², Emrah Tagi ERTUĞRUL ${ }^{3}$ \\ ${ }^{1}$ Süleyman Demirel Üniversitesi, Sütçüler Prof. Dr. Hasan Gürbüz Meslek Yüksekokulu, Isparta \\ 2 İstanbul Ticaret Üniversitesi, Çevre ve Doğa Bilimleri Uygulama ve Araştırma Merkezi, İstanbul \\ ${ }^{3}$ Çanakkale Onsekiz Mart Üniversitesi, Bayramiç Meslek Yüksekokulu, Çanakkale \\ Geliş Tarihi (Received): 09.06.2017, Kabul Tarihi (Accepted): 05.01.2018 \\ $\square$ Sorumlu Yazar (Corresponding author*): halilsuel@sdu.edu.tr \\ (C) +902463512900 边 +902463512901
}

öz

Bazı suni yapıların çevreleri de doğal alanlar gibi kuşlara yaşama alanı olabilmektedir. Kuşlar ise bulundukları yaşam ortamı hakkında fikir veren ve stratejik koruma kararlarının alınmasında kullanılan canlılardır. Bu çalışmanın amacı Karacaören I Barajı çevresinde görülen kuş türlerini ortaya çıkarmak ve popülasyonların korunmasına yardımcı olacak envanter verileri üretmektir. Envanterde, doğrudan sayım tekniklerinden "Noktada sayım yöntemi" kullanılmıştır. Gözlemler, rastgele dağıtılan 54 noktada periyodik olarak gerçekleştirilmiştir. Kuş koruma statülerinin değerlendirmesinde BERN ve CITES sözleşmeleri ile IUCN ve Avrupa Kuşları Kırmızı Listesi'nden yararlanılmıştır. Çalışma sonucunda; 14 takıma mensup 35 familyadan 72 kuş türü tespit edilmiştir. Karacaören I Baraj Göl'ünün birçok kuş türüne ev sahipliği yaparak bu türlerin neslinin devamında rol oynadığı görülmektedir. Karacaören I Baraj Gölü kuşlarına yönelik çalışmaların artırıması sahadaki kuş türleri ile biyolojik çeşitliliğin koruması ve sürdürülebilirliği açısından faydalı olacaktır. Keza mevcut habitatları korumak ve yeni türlerin barınmasına elverecek habitatlar oluşturabilmek için göl çevresini ele alan bir habitat düzenleme ve ıslah planına ihtiyaç vardır.

Anahtar Kelimeler: Karacaören I Baraj Gölü, Kuş türleri, Koruma Statüsü, Kuş çeşitliliği, Habitat Islahı

\section{Bird Fauna of Karacaören I Dam Lake, Isparta-Turkey}

\begin{abstract}
Some artificial structures and surroundings can be habitable areas for birds such as in natural areas. On the other hand, bird species give information about the situation and future of the area they are in, and are used to make strategic conservation decisions. The aim of this study was to reveal the bird species seen around Karacaoren I Dam and to produce inventory data which will help to protect the populations. "Point counts" has been used as a direct counting method in the study. The birds observations were made periodically at a randomly distributed 54 points. The BERN and CITES conventions and the IUCN Red List of European Birds have benefited from the assessment of bird protection status. In the result of study, 72 bird species were identified from 35 families of 14 order. Karacaören I Dam Lake is home to many bird species and plays an important role in the continuity of these species. Thus, increasing of the studies on the birds, which are living in Karacaören I Dam Lake, is important in terms of the conservation and sustainability of biodiversity. There is a need for a habitat arrangement plan to protect existing habitats and also to create new habitats that are favorable for the sheltering of new species.
\end{abstract}

Keywords: Bird species, Karacaoren I dam lake, Protection status, Bird diversity, Habitat rehabilitation 


\section{Giriş}

Ülkemiz kuş çeşitliliği açısından uluslararası önem taşımaktadır (Barış, 2000). Avrupa'da kuluçkaya yatan milyonlarca kuşun büyük bir kısmı güneydeki kışlama alanlarına ulaşmak için ülkemizden geçmekte, bir kısmı da burada konaklamaktadır (Bilgin ve Akçakaya, 1987). Türkiye, göç eden türler için tam bir geçiş rotası konumundadır (Barış, 2000; Kaya, 2015). Türkiye kuş türü bakımında oldukça zengin ve bir çok çalışmada farklı sayıda kuş türü sayıları vardır (Kiziroğlu, 1994; Green ve Moorhouse, 1995; Kirwan ve ark., 1998; Birdlife International, 2008; Kirwan ve ark., 2008; Şekercioğlu ve ark., 2011).

Türkiye farklı coğrafik yapısından dolayı meydana gelen habitat çeşitliliği sayesinde birçok kuş türüne ev sahipliği yapmaktadır. Orman, çayır, fundalık gibi doğal habitatların yanı sıra Baraj gölleri dahil olmak üzere insan eliyle oluşturulmuş alanlar farklı kuş türlerinin beslenme, barınma ve yuvalanma intiyaçlarını karşılarlar (Bilgin, 2000) ve dolaysıyla kuşlara yaşama ortamı olarak önemli alanlar sunarlar (Oğurlu vd., 2005; Kaya, 2015).

Gündoğdu vd. (2009), çalışma alanının yer aldığı bölgeyi de kapsayan Isparta'da yayılış gösteren 251 kuş türünün bulunduğunu bildirmektedir. Isparta çevresindeki yer alan 4 ayrı korunan alanda (Kovada Gölü Milli Parkı, Kasnak Meşesi Tabiatı Koruma Alanı, Yazılı Kanyon Tabiat Parkı ve Gölcük Tabiat Parkı) kuşlardan 32 familyaya ait 4 cins, 83 tür ve 3 alttür gözlemlenmiştir (Gündoğdu, 2002). Isparta çevresinde ise 165 kuş türü görülebilmektedir (Oğurlu ve Gündoğdu, 2004). Tek bir sulak alanda yoğunlaşan gözlemlerde ise daha fazla türün gözlenmesi mümkündür. Mesela, Tabur ve Ayvaz (2005), sadece Kovada Gölü etrafında 153 kuş türü tespit etmişlerdir. Zira sulak alanlar, tropikal ormanlardan sonra biyolojik çeşitliliği en yüksek ekosistemler olup pek çok tür ve çeşitteki canlılar için uygun beslenme, üreme ve barınma ortamı sunmaktadır. Ayrıca sulak alanlar, sadece bulundukları ülkenin değil, tüm dünyanın doğal zenginlik bölgeleridir (Süllü, 2006).

Pek çok kuş türü, doğal dengenin tesisinde önemli rol oynamaktadır (Oğurlu, 2000). Ayrıca, genetik çeşitliliğin devamı için tüm diğer canlılar gibi kuşların da korunması gerekmektedir (Gündoğdu, 2002).

Birçok kuş türü rahatlıkla görülebilen ve işitilebilen canIılar olduğu için iyi birer çevre göstergesidir. Kuş popülasyonlarındaki değişimler çeşitli insan faaliyetlerinin ekosistemleri ve o habitatları paylaşan görülmesi daha zor olan canlıları nasıl etkilediğini göstermektedir (Oğurlu, 2003). Biyolojik çeşitliliğin iyi bir göstergesi olan kuşlar çevreye ilişkin stratejik koruma planlaması kararlarının alınmasında da aynı başarıyla kullanılabilirler (Bibby ve ark., 2006). Bir alandaki kuş türlerinin varlığı, yoğunluğu ve bulundukları alanlarda yı içindeki biyolojik etkinlikleri, alanın mevcut durumu ve geleceği konusunda ön bilgiler verebilen biyolojik ajanlardır (Siriwardena ve ark., 1988).

Kuş türlerinin korunması ve geliştirilmesi ve yine habitatların korunması ancak kuş envanter çalışmaları ile mümkün olmaktadır (Oğurlu, 2003; Gündoğdu, 2005). Kuş türlerin koruma statülerin ortaya konması; nesli tehlike altında türlerin belirlenmesi, yaşama alanlarında yapılacak müdahaleler için envanter gereklidir. Bu çaIışmanın amacı da bu olup Karacaören I Barajı çevresinde görülen kuş türlerini ortaya çıkarmak ve popülasyonların korunmasına yardımcı olacak envanter verileri üretmektir.

Kuş türleriyle ilgili verilen artırılması biyolojik çeşitliliğin korunması ve geliştirilmesi açısından büyük önem arz etmektedir (Akdemir ve Özdemir, 2015). Doğal alanların azalması habitat kayıplarını birlikte getirdiği için birçok hayvan türünün neslini yok olma tehlikesiyle karşı karşıya bırakmıştır (Avcı vd., 2005). Buna mukabil arazi kullanım tarzındaki bazı değişimler yaban hayatını olumlu yönde de etkileyebilmektedir. Mesela barajlar, göletler gibi suni yapıların, su kuşları açısından yeni yaşama alanları oluşturması olumlu yöndeki değişimlere örnek olarak gösterilebilir (Ünlü, 2005).

Zira, kuşların hayatını tehdit eden kirlilik, kaçak avlanma, gibi muhtelif etkenler varsa da kuş türleri için asıl tehlike kuş habitatlarının yok olmasıdır. Kuşların hayatını sürdürmeleri, üremek ve yavru yetiştirebilecekleri güvenli yerler bulmasına bağlıdır (Brooks ve Gibbs, 2000). Baraj göl ve göletleri ise bu anlamda kuşlara alternatif habitatlar sunabilmektedir. Muhtelif habitat tiplerinin farklı ekolojik intiyaçları olan türlerin çeşitli intiyaçlarına cevap verebilmesi sayesinde baraj gölleri de bulunduğu alana zenginlik katarak tür zenginliğinin yolunu açabilir (Kılıç, 1999).

\section{MATERYAL VE YÖNTEM}

\section{Çalışma alanı}

Karacaören I Barajı: Burdur İli Bucak İlçesinin 35 km güneydoğusunda, Isparta İli Sütçüler ilçesinin $28 \mathrm{~km}$ güneybatısında yer alır. Aksu ırmağı üzerinde 1989 yılında inşası tamamlanan baraj, sulama, taşkın önleme ve enerji üretimi amacıyla kurulmuştur. $1234 \mathrm{hm}^{3}$ hacmi ve 4550 ha rezervuar alanına sahiptir. Sütçüler ilçesinin Çandır, Melikler, Şeyhler gibi köylerinin ve çevredeki tarım alanlarının su kaynağı Karacaören I Baraj Gölü'dür. Yıllık enerji üretimi $142 \mathrm{GWh} /$ yıl'dır. Ayrıca gölde kafes balıkçılığı da yapılmaktadır. Kara- 
caören I Baraj Gölü üzerinde bir ada ve bir yarımada mevcuttur. Adanın alanı 6 ha, yarımadanın yüzölçümü 18 hektardır. 16000 ha büyüklügünde olan baraj havzası çalışma sahası olarak belirlenmiştir (URL1, 2006). Yörenin yıllık ortalama sıcaklığı $13.1 \mathrm{C}^{\circ}$, yıllık yağış miktarı 950.1 mm'dir (DMi, 2006). Karacaören I Baraj Gölü'nün rakımı 280 m'dir. Çalışma alanın içeresinde 5 adet ada ve 3 adet yarım ada vardır. Bu adalara yine orman, çalı ve otsu vejetasyonla kaplıdır.

\section{Kuş Gözlemleri}

Kuş türlerinin envanterinde doğrudan sayım tekniklerinden "Noktada sayım yöntemi" kullanılmıştır (Oğurlu, 2003). Kuş gözlemleri sahaya hâkim ve gözlem yapmaya elverişli olan ve rastgele olarak dağıtılan 54 noktada gerçekleştirilmiştir. Bu gözlemler iki aşamalı olarak yapılmıştır. 2006 yılı temmuz ayında arazisi tamamlanan yüksek lisans tez verileri 2016 Haziran - 2017 Mayıs ayları arasında 11 aylık arazi gözlemiyle tekrar kontrol edilmiştir. Gözlemler genel olarak her ayın başına, ortasında ve sonunda olmak üzere; toplam $5-6$ günlük periyotlar halinde yapılan gözlemler, hava şartları uygun olduğu sürece sabah gün doğumundan akşam gün batımına kadar sürdürülmüştür. Gözlemlerde, $10 \times 50$ Konus ve $16 \times 50$ Pentax büyütmeli dürbünler ile Nikon 25-75x82 teleskop kullanılmıştır. Gözlenen bireylerin teşhisinde Bang ve Dahlstrom (1980), Kiziroğlu (1989), Heinzel ve ark., (1995), Milli Parklar ve AvYaban hayatı Genel Müdürlüğü'nün (2000) kitaplarından ve bilimsel isimleri içinde güncel yayınlardan (Keten ve ark., 2010; Öztürk, 2017) yararlanılmıştır. Türkçe isimlerin verilmesinde ve Türkiye'deki göç statülerinin belirlenmesinde ise Türkçe kuş isimleri listesi (Bilgin, 2000) ve Türkiye ve Avrupa'nın Kuşları (Heinzel ve ark., 1995) esas alınmıştır. Göç statülerindeki kısaltmalar H: Yerli Kuş (Her zaman görülen), K: Kış göçmeni, Y: Yaz göçmeni ve G: Geçit kuşu şeklide kullanılmıştır (Heinzel ve ark., 1995). Kuş koruma statülerinin değerlendirmesinde BERN ve CITES sözleşmesi ekleri, IUCN ve Avrupa Kuşları Kırmızı Listesi (Dizdaroğlu, 2015)'nden yararlanılmıştır.

\section{BULGULAR}

Çalışma sahasında yapılan gözlemler sonucunda sahada 14 takıma mensup 35 familyadan 72 kuş türü tespit edilmiştir. Kuş türlerinin takımlara dağılımı; Galliformes 2 tür, Anseriformes 6 tür, Podicipediformes 2 tür, Columbiformes 3 tür, Caprimulgiformes 1 tür, Gruiformes 1 tür, Ciconiiformes 6 tür, Pelecaniformes 1 tür,
Charadiiformes 4 tür, Strigiformes 2 tür, Accipitriformes 1 tür, Coraciiformes 2 tür, Piciformes 1 tür, Falconiformes 6 tür ve Passeriformes 34 tür Kuş türlerinin en yaygın olarak toplandığı takımın Passeriformes olduğu görülmektedir. Ülkemize göre statüleri değerlendirildiğinde alandaki kuş türlerinin 42'u yerli (\% 58), 18' si yaz göçmeni (\% 25), 11'i kış göçmeni (\% 15) ve 1'i geçit kuşu (\% 2) olduğu belirlenmiştir.

Uluslararası Doğa Koruma Birliği (IUCN)'in verileriyle çalışmada teşhis edilen türler karşılaştırıldığında sahadaki türlerin tehlike altında olmadıkları görülmekte, buna mukabil 2015 yılında hazırlanan Avrupa Kuşları Kırmızı Listesi'ne göre bu çalışmada tespit edilen bazı türlerin koruma statülerinin farklı olduğu görülmektedir. Mesela, Circus cyaneus (Gökçe Delice), Alectoris chukar (Kınalı keklik), Fulica atra (Sakarmeke), IUCN kriterlerine göre LC (Asgari endişe) seviyesindeyken Avrupa da bu türleri NT (Neredeyse tehdit altında) seviyesinde olduğu görülmektedir. Streptopelia turtur (Üveyik) ve Alcedo atthis (Yalıçapkını) IUCN'ne göre LC (Asgari endişe) Avrupa'da VU (Hassas) seviyesinde görülmektedir. Avrupa Kuşları Kırmızı Listesine göre tüm Avrupa ve 27 Avrupa birliği ülkesinde kuşların koruma statülerinde farklılıklar vardır. Tadorna ferrugine (Angıt) Avrupa'da LC kategorisinde iken 27 Avrupa Birliği ülkesinde NT seviyesine düşmektedir. Circus cyaneus (Gökçe delice), Alectoris chukar (Kınalı Keklik) ve Fulica atra (Sakarmeke) Avrupa'ya göre NT seviyesindeyken 27 Ab ülkesi ve IUCN göre LC kategorisine yükselmektedir. Streptopelia turtur (Üveyik) Avrupa'ya göre VU, 27 AB Ülkesine göre NT ve IUCN'e göre ise LC seviyesinde olduğu görülmektedir. Fringilla montifringilla (Dağ ispinozu) Avrupa ve IUCN göre LC seviyesinde iken 27 $A B$ ülkesine göre $V U$ seviyesindedir.

Avrupa'nın Yaban Hayvanları ve Yaşam Ortamlarının Korunması (BERN) Sözleşmesine göre 34 kuş türü kesin koruma altında (Ek-II: Kesin Koruma Altında Hayvan Türleri), 21 kuş türü ise koruma altında (Ek-III: Koruma Altındaki Hayvan Türleri) diğer türler ise herhangi bir ekte yer almamaktadır.

Nesli tehlikedeki yabani hayvan ve bitki türlerinin uluslararası ticaretine (CITES) ilişkin sözleşmeye göre 6 kuş türünün Ek-2 (Nesilleri mutlak olarak tükenme tehdidiyle karşı karşıya olmamakla birlikte, nesillerinin devamıyla bağdaşmayan kullanımları önlemek amacıyla ticaretleri belirli esaslara bağlanan türleri içerir) listesinde olduğu görülmektedir. 
Tablo 1. Karacaören I Baraj Gölünde Gözlemlenen Kuş Türleri ve Koruma Statüleri

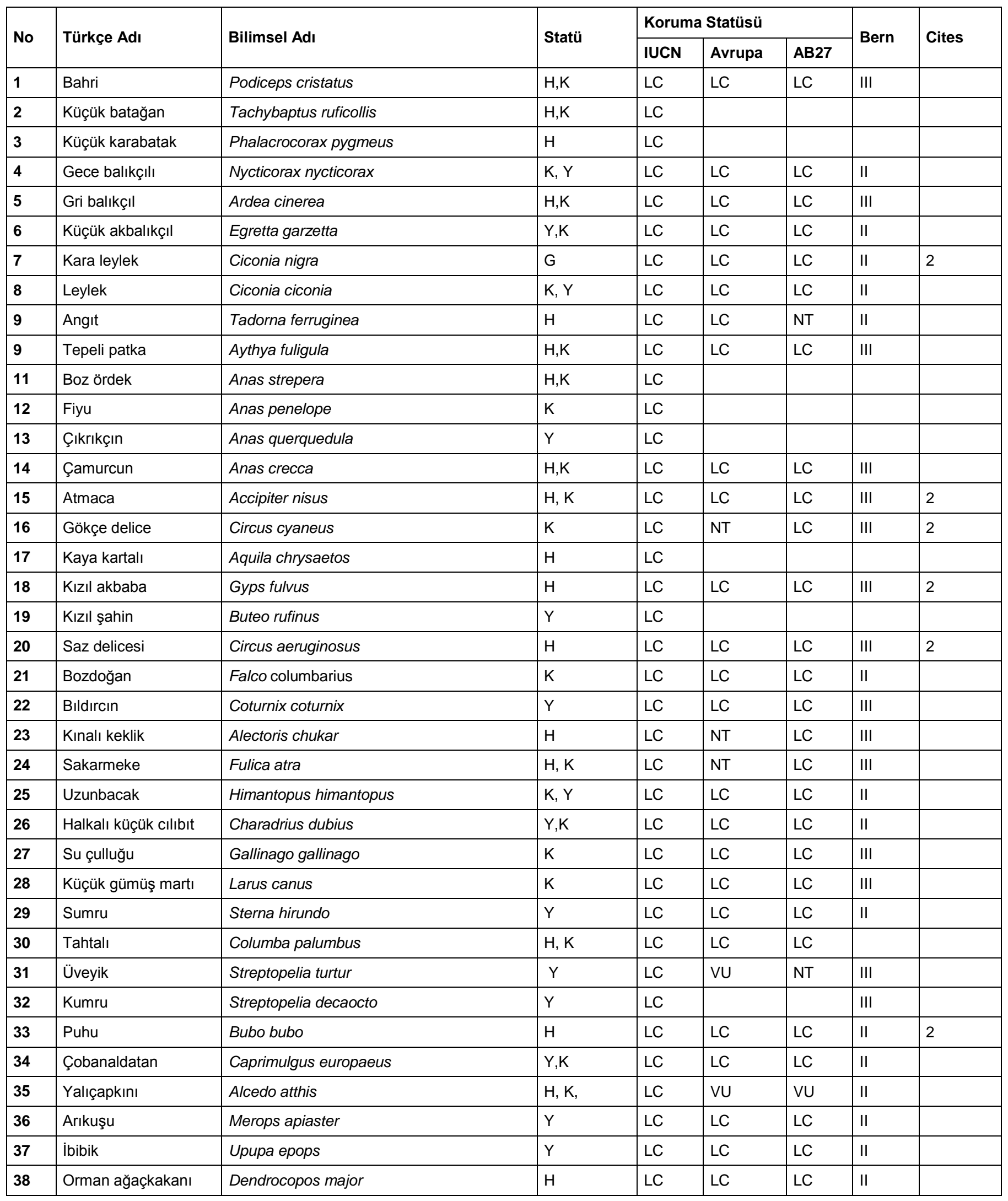




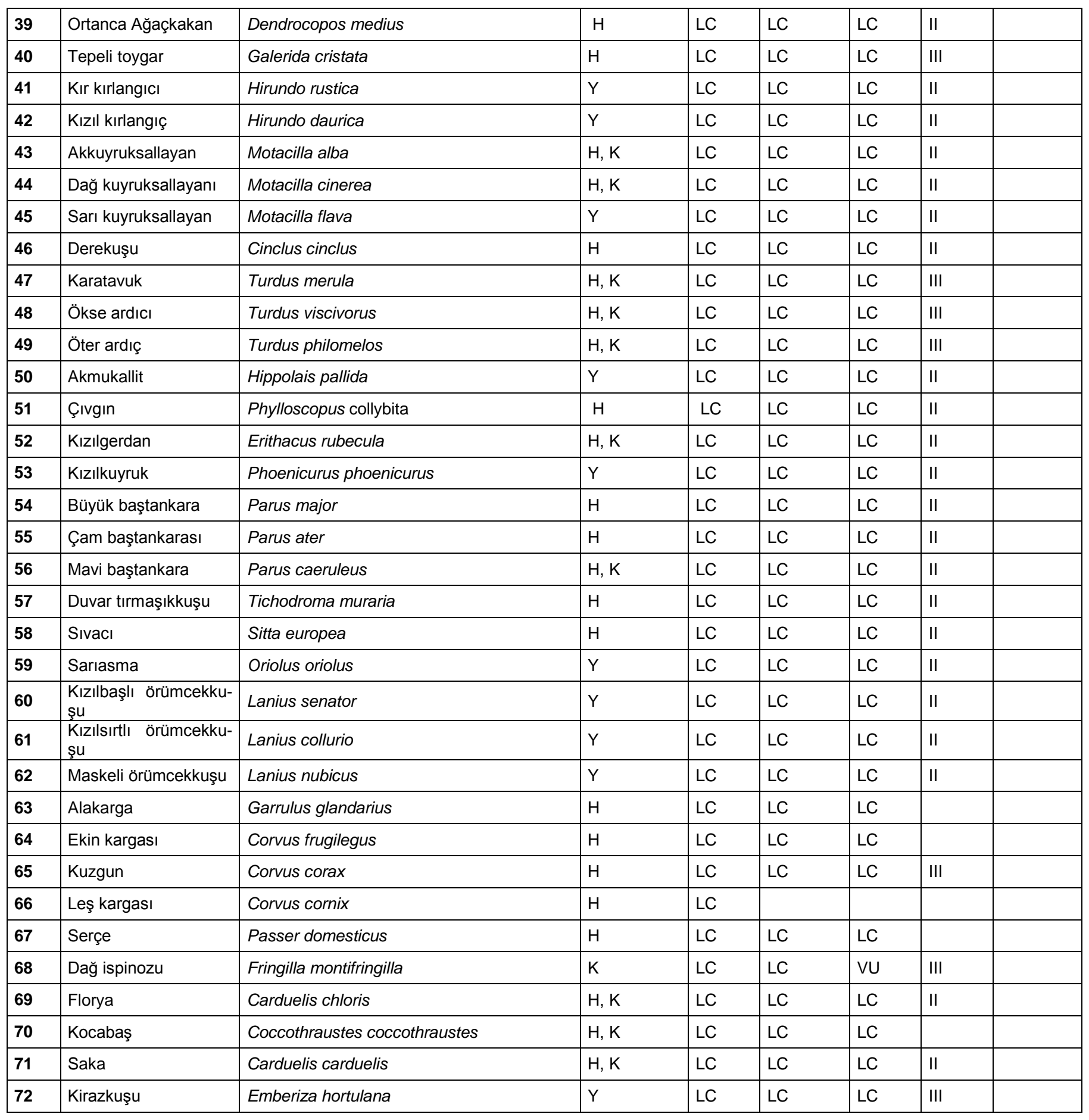

\section{SONUÇ VE TARTIŞMA}

Karacaören I Baraja gölünde yapılan araştırma sonucunda 72 farklı kuş türü tespit edilmiştir. Bu sayı Türkiye'de görülen kuş türlerinin \% 15'ne, Isparta'da görülen türlerin \% 44'üne ve Isparta'da milli park statüsüyle korunan Kovada Gölü Milli Parkı kuş türlerinin ise \%47'sine tekabül etmektedir. 1992 inşa edilmiş gölde sazlık gibi özellikle su kuşları için uygun habitatlar azdır. Dolayısıyla kuş türü sayısı aynı bölgede bulunan sözgelimi Eğirdir (Tabur ve Ayvaz, 2005) ve Kovada (Tabur ve Ayvaz, 2006) göllerindeki kuş türü sayısına göre oldukça düşük seviyededir. Fakat buna rağmen, doğal karakterini tamamen koruyabilmiş Kovada gölünü barındıran Kovada Milli Parkının neredeyse yarısı kadar kuş türünün gözlenebilmesi, insan eliyle yapılmış 
göl için küçümsenecek bir rakam değildir. Şayet, gölü çevreleyen alanlarda miktarı pek yetersiz kalan sazlık benzeri habitatlar geliştirilebilirse bu rakamın artma imkânı bulunmaktadır. Yani göl çevresinde kuşlara hitap edecek bir habitat ıslahına ihtiyaç vardır. Çalışma sonucundan Karacaören I Baraj Gölündeki kuş türlerinin \% 56'sının göçmen olduğu tespit edilmiştir. Dolayısıyla yıl içerisinde tür çeşitliliği de değişebilmektedir (Gündoğdu, 2002; Arslangündoğdu, 2010; Beşkardeş, 2012; Aksan ve Mert, 2016). Yine göçmen kuşların olması alanların beslenme, barınma ve üreme gibi faaliyetler açısında önemli olduğunu ortaya koymaktadır (Keten ve ark., 2012).

Karacaören I Baraj Gölündeki kuş türlerinin koruma statülerinde bakıldığında BERN sözleşmesine göre 37 türün kesin koruma, 21 türün ise koruma altında olduğu görülmektedir. Dolayısıyla yapay alanların her zaman olumsuz sonuçlara yol açmadığı bazen habitat gereksinimlerinin bir kısmını karşıladığı için türler açısından faydalı olduğu ortaya çıkmaktadır (Ünlü, 2005). Karacaören I Baraj Gölü'nde de böyle bir durumun ortaya çıktığı ve Göl'ün koruma açısından birçok kuş türüne ev sahipliği yaparak bu türlerin neslinin devamı için önemli rol oynadığı görülmektedir. CITES sözleşmesine bakımında değerlendirildiğinde; nesillerinin devam etmesi yönüyle herhangi bir sorun olmayan ancak ticaretlerinin yapılmasıyla nesilleri tehlikeye düşebilecek 6 kuş türünü Karacaören I Baraj Gölünü kullandığı gözlenmektedir.

IUCN ve Avrupa Kuşları Kırımızı listesine göre koruma statülerinin türlere göre değiştiği görülmektedir. Bu değişiklerin genel olarak kuş türlerine ait verilerin yetersiz ya da uygun toplanmamasından kaynakladığı söylenebilir. Dünyada kuşların ve diğer canlı türlerinin koruma statüleri için birçok sözleşme imzalandığı bilinmektedir (Dizdaroğlu, 2015). Tüm ülkeler kuş türleri için kendileri özgü politikalar geliştirerek çalışmalar yapmaktadır. Bu sebeple de kuş türlerinin koruma statülerinde farklılar ortaya çıkmaktadır. Belirli bir coğrafi alandaki tür sayısı, tür çeşitliliği, genetik çeşitlilik ve biyolojik çeşitlilik ancak farklı disiplinlerin iş birliği ve uygun envanter teknikleri kullanarak sağlanabilir (Gülsoy ve Özkan, 2008; Negiz vd., 2015). Bu yüzden her ülkenin türlere ait çalışmaları uygun politika ve yöntemlerle artırması türlerin korunması açısından çok önemlidir. Karacaören I Baraj Gölü gibi yapay alanlarda da kuş türleri ile ilgili çalışmaların artırılması tür çeşitliliği, genetik çeşitlilik ve biyolojik çeşitliliğin koruması ve sürdürülebilirliği açısından faydalı olacaktır. Çünkü kuş çeşitliliğinin, ekosistemin toplam çeşitliliğini yaklaşık olarak temsil ettiği bilinmektedir (Reif ve ark., 2016). Sonuç olarak ta mevcut türlerin kullandığı habitatları korumak ve yeni türlerin barınmasına elverecek habitat- lar oluşturabilmek için göl çevresini ele alan bir habitat düzenleme ve ıslah planına intiyaç vardır.

\section{TEŞEKKÜR}

Çalışmamızı 1278-YL-06 numaralı proje ile destekleyen Süleyman Demirel Üniversitesi Bilimsel Araştırma Projeleri Yönetim Birimi'ne teşekkür ederiz. Bu çalışma 11-13 Mayıs 2017 tarihleri arasında Kayseri'de düzenlenen Ecology 2017 isimli uluslararası sempozyumda "Bird Fauna of Karacaören I Dam Lake" başlığı ile özet metin olarak yayınlanmıştır.

\section{KAYNAKLAR}

Akdemir, D., Özdemir, İ. (2015). Batı Akdeniz Bölgesi'ndeki kızılçam ormanlarında uygulanan tıraşlama kesimlerinin kuşlar üzerindeki etkileri. Turkish Journal of Forestry 16(2): 102-110.

Aksan, Ş., Mert, A. (2016). Bird Species in Isparta-Atabey Plain (Isparta Atabey Ovası'nın Kuş Türleri). Turkish Journal of Forestry 17(2): 153-157.

Arslangündoğdu, Z. (2010). Bird Species and Their Abundance in Istanbul Belgrad Forest. İ.Ü. Orman Fakültesi Dergisi 60 (1): 14-28.

Avcı, M., Oğurlu, İ., Sarıkaya, O. (2005). Kasnak Meşesi Tabiatı Koruma Alanı Faunası Üzerine Araştırmalar. Korunan Doğal Alanlar Sempozyumu, Sözlü Bildiriler Kitabı, 599-606s.

Bang, P., Dahlstrom, P. (1980). Animal Tracks and Signs. St. James's Place, No: 13, London.

Barış, S. (2000). Kuşların Otoyolu. Yeşil Atlas 3: 81-83.

Beşkardeş, V. (2012). Yedigöller ve Yeşilöz Yaban Hayatı Geliştirme Sahaları avifaunası üzerine araştırmalar. SDU Faculty of Forestry Journal 13: 28-34.

Bibby, C., Jones, M., Marsden, S. (2006). "Keşif Gezisi Arazi Teknikleri, Kuş Araştırmaları". Doğa Koruma Merkezi, Sancar Barış, Barbaros Demirci, Doğa Derneği, Ankara $11-100 \mathrm{~s}$.

Bilgin, C. (2000). Gökyüzüne Dargın Kuşlar. Gezi Dergisi 29: 92-99.

Bilgin, C., Akçakaya, H. R. (1987). Türkiye'nin Biyolojik Zenginlikleri. Türkiye'nin Çevre Sorunları, Fakülte Yayınları, 161, Ankara, 183-202.

Birdlife International, (2008). State of World's Birds: Indicators for Our Changing World. Birdlife International Cambridge, UK.

Brooks, F., Gibbs, B. (2000). Kuşlar. TÜBiTAK, Ankara.

Dizdaroğlu, E. (2015). Avrupa Kuşları Kırmızı Listesi. BirdLife International (2015) Avrupa Kuşları Kırmızı Listesi, Lüksemburg Avrupa Toplulukları Resmi Yayın Ofisi. Türkçe baskı editörleri: Osman Erdem, İlker Özbahar, Güler Bozok. Doğa Araştırmaları Derneği, Ankara 82s.

DMi, (2006). Devlet Meteoroloji İstasyonu Verileri. Online veri, Ankara.

Green, I., Moorhouse, N. (1995). A Birdwatchers' Guide to Turkey, Prion Ltd., Perry.

Gülsoy, S., Özkan, K. (2008). Tür Çeşitliliğinin Ekolojik Açıdan Önemi Ve Kullanılan Bazı İndisler. SDÜ Orman Fakültesi Dergisi 1: 168-178. 
Gündoğdu, E. (2002). Isparta Çevresindeki Bazı Korunan Alanlarda Orman Kuşları Üzerine Gözlemler. SDÜ Orman Fakültesi Dergisi A(1): 83-100.

Gündoğdu, E. (2005). Türkiye'de Yaban Hayatı Envanteri ve Koruma Problemleri: Isparta Örneği. Çevre ve Ormancılık Şurası "Tebliğler" Mart 2005 / Antalya, 4.Cilt, 1389-1496s.

Gündoğdu, E., Türkay, O. Ç., Ertuğrul, E. T. (2009). Isparta'nın Kuşları. Bezelye Reklam, Isparta.

Heinzel, H., Fitter, R., Patslow. J. (1995). Birds of Britain and Europe with North Africa and The Middle East. HapperCollins Publishers Ltd., ISBN 97897594098281, England.

IUCN, (2017). The IUCN Red List of Threatened Species. http://www.iucnredlist.org/ Erişim tarihi: 24 Ocak 2017.

Kaya, M. (2015). İğneada Longoz Ormanları ve Çevresinin Kuşları. Trakya University Journal of Natural Sciences 16(1): 31-43.

Keten A., Arslangündoğdu Z., Selmi E., (2012). "Düzce-Efteni Gölü Kuş Türleri", Düzce Orman Fakültesi Ormancılık Dergisi, 8: 10-18.

Keten A., Beşkardeş V., Arslangündoğdu Z., (2010). "Observation On Ornithofauna Of Kocaeli-Yuvacik Dam Watershed In Turkey", Journal of Environmental Biology, 31: 189-195.

Kılıç, A. (1999). Karapınar (Konya) Yöresinin Kuşları. Turk Journal of Zoology, Ek Sayı 1:91-97.

Kirwan, G. M., Martins, R. P., Eken, G., Davidson P. (1998). Checklist of the Birds of Turkey. OSME Sandgrouse Supplement 1, USA.

Kirwan, G., Welch, H., Demirci, B., Boyla, K.A., Castell, P., Özen, M., Marlow, T. (2008). The birds of Turkey. Cristopher Helm Publishers Ltd., London.

Kiziroğlu, İ. (1989). Türkiye Kuşları. Orman Genel Müdürlüğü Basımevi, No: 186, Ankara.

Kiziroğlu, İ. (1994). Canlıların Yok Olma Süreci ve Anadolu'da Soyu Tükenme Tehlikesi Altındaki Kuş Türleri. Tabiat ve İnsan 3: 2-4.

Negiz, M.G., Gülsoy, S., Özkan, K. (2015). Orman Ekosistemlerinde Tür Çeşitlilik Bileşenlerinin Belirlenmesinde Kullanılabilecek Bir Arazi Envanter Yaklaşımı. Süleyman Demirel Üniversitesi Fen Bilimleri Enstitüsü Dergisi 19(2): 198-204.

Oğurlu, İ. (2000). Biyolojik Mücadele. SDÜ Yayınları, 8, Isparta.
Oğurlu, İ. (2003). Yaban Hayatında Envanter. T.C. Çevre ve Orman Bakanlığı Doğa Koruma ve Milli Parklar Genel Müdürlüğü, Isparta.

Oğurlu, İ., Gündoğdu, E. (2004). Birds Observations in Isparta. International Eurasian Ornithology Congress, 8-11 April 2004, 35-41s.

Oğurlu, İ., Gündoğdu, E., Sarıkaya, O. (2005). Gölcük Tabiat Parkı Faunası Üzerine Araştırmalar. Korunan Doğal Alanlar Sempozyumu Sözlü Bildiriler Kitabı, 615-621s.

Öztürk, Y. (2017). Bird diversity and conservation status in Isparta province (Turkey). Journal of Environmental Biology, 38(5(SI)), 971-980.

Reif, J., Hanzelka, J., Kadlec, T., Štrobl, M., Hejda, M. (2016). Conservation implications of cascading effects among groups of organisms: the alien tree Robinia pseudacacia in the Czech Republic as a case study. Biol. Conserv. 198: 50-59.

Siriwardena, G M., Baillie, S. R., Buckland, S. T., Fewster, R. M., Marchant, J. H. and Wilson, J. D. (1988). Trends in the Abundance of Farmland Birds: a Quantitative Comparison of Smoothed Common Birds Census Indices. Journal of Applied Ecology 35: 24-43.

Süllü, N. (2006). Konya-Ereğli Akgöl'ün Avifaunası. Selçuk Üniversitesi, Fen Bilimleri Enstitüsü, Yüksek Lisans Tezi, Konya.

Şekercioğlu, C.H., Anderşon, Ş., Akçay, E., Bilgin, R., Emre Can, Ö., Semiz, G., Tavşanoğlu, Ç., Baki Yokeş, M., Soyumert, A., İpekdal, K., Şağlam, İ. K., Yücel, M., Dalfes, H.N. (2011). Turkey's globally important biodiversity in crisis. Biological Conservation 144 (12): 2752-2769.

Tabur, M. A., Ayvaz, Y. (2005). Kovada Gölü Ornitofaunistik Önemi. Korunan Doğal Alanlar Sempozyumu Sözlü Bildiriler Kitabı, 587-594s.

Tabur, M.A., Ayvaz. Y. (2006). Ornithofauna of Lake Eğirdir. Bulletin of Pure and Applied Sciences, 25 A (2): 75-84.

URL1 (2006). Karacaören I Barajı. http://www.isparta.gov.tr/index3.php?goster=2\& b 1=1\&b2=7\&b3=6. (Erişim Tarihi: 05.02.2006)

Ünlü, E. (2005). Gap'ın Ekolojik Etkileri. http://www.dicle.edu.tr/ halks/ kon12.htm (Erişim Tarihi: 03.Mart.2005) 